\title{
Energy Transition Patterns of Households in South Africa
}

\author{
Naseer Babangida Muazu* $\quad$ Sani Saidu ${ }^{\dagger} \quad$ Yahaya Saleh Ibrahim ${ }^{\ddagger}$
}

\begin{abstract}
Despite the attainment of $87 \%$ electricity access, majority of the middle and low-income households in South Africa are faced with the huge challenge of transition from fuel wood to electricity for domestic activities especially cooking and heating. This article highlights the role of demographic variables in household decisions to use fuel wood instead of electricity in the Province of the Western Cape. We employed a quantitative cross-sectional survey design and a two-stage stratified random sampling technique to capture 1199 respondents using Enumeration Areas (EAs) demarcated to the province for the 2011 Census. Using chi-square and multivariate analysis, the outcome of the study shows a significant relationship and causality between choosing fuel wood as an energy source and household living circumstances such as marital status, education level, and age. From the results, it is indicative that a clear linkage exists between household living circumstances and consumption of dirty energy. To achieve a smooth transition from fuel wood to electricity, the study recommends policies that would influence household behavior such as investment in human capital and environmental education.
\end{abstract}

Keywords: Energy transition, demographic variables, fuel-wood consumption, influence, Western Cape Province.

\section{Introduction}

Understanding household energy transition patterns in developing countries, including South Africa, is important especially for policies that support universal access to clean energy for environmental sustainability. Household energy use pattern, to a large extent, represents the status, welfare, and stage of economic development of any country. The link between various energy types broadly categorized as traditional (biomass) energy which includes fuel wood, charcoal, and agricultural residue; and modern (clean) energy which includes kerosene, LPG, electricity and solar, and household activities, such as cooking, boiling, heating (or cooling), lighting, ironing among other things is well documented in the literature. Currently, more than 2.7 billion people in developing countries primarily rely on traditional biomass for cooking and heating (Muller \& Yan, 2018). In South Africa, fuel wood remains the second most common energy source for cooking despite the attainment of $87 \%$ electricity acces. The use of fuelwood as household energy is also common in countries such as Brazil (52.9\%), Ecuador (63.2\%), Vietnam (60\%), and Nigeria (72\%) (Kuunibe, Issahaku, \& Nkegbe, 2013; Muazu \& Ogujiuba, 2020).

\footnotetext{
*Centre for Energy and Environmental Strategy Research, Kaduna State University, Nigeria.

Email: nmbabangida69@gmail.com

${ }^{\dagger}$ Faculty of Management Sciences, Bauchi State University Gadau, Nigeria.

$\ddagger$ Centre for Energy and Environmental Strategy Research, Kaduna State University, Nigeria.
} 
Despite intensive research, the knowledge about the determinants of household energy transition remains limited and the influence of factors that are driving the transition varies spatially. For this reason, Muller and Yan (2018) argue that the actual impact of energy prices on household energy substitution is still debatable. Other studies have found that age is positively associated with preference for fuel wood use and some show that age is instead positively associated with preference for modern energy. Education influences fuel wood use negatively (Lay et al. 2013). Likewise, family size influences energy transition as large families in Africa are often related to lower incomes as a result they have limited capacity to afford modern energy instead they use traditional energy.

In South Africa, irrespective of whether households are electrified or non-electrified low-income households incorporate electricity in their energy mix for lightening purpose only (despite government subsidy on electricity (FBE), while fuel wood and other dirty fuels are the main energy sources that are used for cooking and heating. Matsika, Erasmus, and Twine (2013) found 68\% of the rural households that have electricity access still use fuel wood as the primary energy due to cost-saving purposes. Furthermore, the yearon-year changes in household energy use between 2011 and 2012 show that the use of fuel wood among the non-electrified households has risen from $65 \%$ to $74 \%$, while the level of household's reliance on electricity remains relatively unchanged (HSRC and DoE, 2013).

In recent times, the household energy transition has been receiving growing attention in developing countries because fuel wood consumption is one of the causes of global warming, climate change, and diseases, and several studies have investigated driving factors of the transition. Even though different conclusions have been reached concerning the effects of these factors, there is a need for more research in the area especially in the Western Cape Province where informal settlements are mixed with formal settlements. This is despite the general increase in electricity connectivity in the province, Western Cape Government (2013) had reported that the proportion of people who use electricity for domestic purpose are decreasing. Furthermore, most of the empirical findings on drivers of household fuel wood consumption in the country were largely due to increasing electricity tariff (Franks, 2014; Franks \& Prasad, 2014) while demographic drivers such as age, marital status, and education level have not been fully explored. The present study intends to add to the existing literature through a combination of chi-square and multivariate analyses to shed more light on reasons for fuel wood consumption to facilitate a design of policy on clean energy for environmental sustainability

\section{Literature Review}

\section{Theoretical Framework}

\section{Energy Ladder Hypothesis}

The pattern of household energy use in developing countries has led to the emergence of two contrasting theories that explain how households switch from traditional energy to modern energy. The energy ladder hypothesis and fuel stacking hypothesis captured the factors that influence household energy transition. According to the energy ladder 
hypothesis, income rise gives households the ability to discontinue using traditional fuels that are dirty and continue with more efficient clean energy. The household will first move to transition fuels (charcoal and kerosene), and, finally to modern fuels (electricity and LPG). However, due to the complexity of household energy use and energy switching processes in developing countries, much academic literature criticized the energy ladder hypothesis. The early critics were Masera, Saatkamp, and Kammen (2000). They argue that even though an increase in household income can increase the uptake of modern energy, changes in relative prices of fuels do also influence the type and quantity of energy consumed. Cultural and social factors may make households behave contrary to these expected patterns. Factors such as the education level of the household, dwelling characteristics, preparation of traditional meals, and gender of the head of the households could also contribute to the complexity of the energy ladder hypothesis.

In light of the emergence of large empirical evidence that undermines the general principle and specification of the energy ladder hypothesis, the energy stacking hypothesis came about as an alternative in explaining household energy transition (Masera et al., 2000). According to the hypothesis, as the income of the household increased, the transition towards the use of modern energy takes place in the context of the simultaneous use of various types of energy. In this view, income increase makes households adopt the use of modern energy, but at the same time continue using traditional energy for some activities, thus 'mixing' various energy sources. Therefore, when household income increases they adopt the use of modern energy, but also continue using traditional energy for some activities such as cooking and heating (Elias \& Victor, 2005). Fuel stacking behavior is seen as a livelihood strategy that enables the household to cope with unstable income flows, protect themselves from fragile markets and hold on to their cultural practices while benefiting to some extent from modern energy.

\section{Multi-Fuel/ Fuel Stacking Hypothesis}

The fuel Stacking hypothesis becomes an alternative explanation for household energy consumption behavior in developing countries. Contrary to the energy Ladder hypothesis, the fuel stacking hypothesis suggests that many households in the developing countries do not completely switch or substitute fuels, rather simultaneously use multiple fuels at all levels of the energy ladder. In other words, households do not completely switch to modern energy when their status increases instead consume a combination of different fuels. According to the fuel stacking hypothesis, households don't completely switch, but multiple stacking is followed, whereby new fuels and technologies for cooking are added to the existing traditional fuels. The household income increase only makes them adopt the use of modern fuels, but at the same time continue using traditional fuels for some activities, thus 'mixing' various energy sources. There are reasons for the household's refusal to abandon traditional energy. Firstly, households may not have enough funds to immediately purchase new energy-consuming appliances at the time they gain access to new energy more especially in the situation where they have invested significantly in "traditional" technologies (e.g. wood-burning stoves). Secondly, the expensive nature of modern energy services. Finally, multiple fuels can provide a sense of energy security 
as complete dependence on commercial fuels leaves households vulnerable to variable prices, and often their services are unreliable.

\section{Empirical Literature}

The empirical literature has shown that households in the developing country consume multiple energy for several reasons. Firstly, since households have an already existing investment in traditional energy like wood-burning equipment and may not have excess money to buy all the equipment that suits modern energy such as LPG and electricity they can continue to use fuel wood alongside modern energy. Secondly, the expensive and unreliable nature of modern energy services propels households to have a backup. Studies have confirmed the effort of the households to use different energy types to satisfy their energy requirements. For example, in Guatemala, Taylor, Moran-Taylor, Castellanos, and Elías (2011) revealed that fuel-wood was maintained by $77 \%$ of the migrant households as a primary energy source despite ownership of LPG. Ogwumike, Ozughalu, and Abiona (2014) found that households stack different forms of fuels due to supply constraints. In Ethiopia, Mekonnen, Gebreegziabher, Kassie, and KÖLIN (2009) report that households in the Northern part of the country use a multi-fuels strategy. Therefore, a household's multi-fuel energy behavior has become a livelihood strategy that enables them to cope with unstable income flows, protect themselves from fragile markets, and hold on to their cultural practices while benefiting to some extent from modern fuels. Whether households stack or switch to another energy type, certain factors will doubtfully drive the behavior. The most noted factors found by most of the studies are socioeconomic and demographic factors. Income is found to be the major driver behind energy transition (Muller \& Yan, 2018). In China, a study has found that rural households respond to changing income by substituting coal for fuel wood (Démurger \& Fournier, 2011) but in Zimbabwe, urban households were found to move away from fuel wood to kerosene and electricity due to income rise. The influence of age is significant on household energy transition as older heads of the household prefer fuel wood to electricity in Bhutan but in rural Ethiopia, a study shows that older household head is more likely to prefer modern energy to traditional energy (Guta, 2012). Household energy transition is also determined by the household size a recent study indicated that larger households prefer dirty energy in Turkey (Özcan, Gülay, \& Üçdoğruk, 2013). However, the opposite trend was found in Nigeria where larger households choose clean energy over dirty energy. In terms of the influence of education level on household energy transition, the study of Gebreegziabher, Mekonnen, Kassie, and Köhlin (2012) in Ethiopia show that, the higher the household education level, the less likely they will choose fuel wood, while the more likely they will choose electricity. Likewise, in Kenya, Lay, Ondraczek, and Stoever (2013) show that higher education level is associated with a lower probability of fuel wood consumption and a higher probability of using electricity and solar energy. There seems to be a consensus in the literature that higher education level is associated with clean energy use instead of dirty energy. Empirical evidence on the influence of gender on household energy transition shows that the proportion of the female member's induced households to use fuel wood in Nepal signifying that women are the main gatherers of fuel wood 


\section{Methodology}

\section{Study Area}

Western Cape Province is located on the southwestern coast of South Africa. It is the fourth largest province in the nine provinces in South Africa, and the third most populated with an estimated population of 6.5 million people as of 2017. In 2012, Western Cape Province was rated as the second most affluent province in South Africa scoring $30.6 \%$ (StatsSA 2012), and more than $90 \%$ of the households use electricity for household activities even though Statistics SA (2012) revealed that the use of electricity for heating purposes has decreased. This is most likely due to the high cost of electricity being experienced in the country as a result of the ESCOM crisis. Furthermore, Franks (2014) have shown that still there is a significant portion of the population within the province that either does not have access to the electricity supply by the national grid or cannot afford the cost of electricity.

\section{Source of Data}

The study used a cross-sectional survey design involving administering a questionnaire to the respondents. We used 608 enumeration areas (EAs) demarcated for Western Cape Province during the 2011census in South Africa to administer the questionnaire to the household fuel-wood consumers. Three censuses were conducted in South Africa since the first democratic elections in 1994 (1996, 2001, and 2011). Census 2011 has captured many populations and household attributes as well as a variety of indicators (Census, 2011) that immensely helped the study.

\section{Sampling Technique}

A two-stage random sampling technique was used to randomly administer the questionnaire to two (2) household ( $\mathrm{HH})$, fuel-wood consumers, from each Enumeration Area (EA). A total of 1199 household $(\mathrm{HH})$ responses were collected in the 608 enumeration areas (EAs) demarcated to the Western Cape Province given the response rate of 85

\section{Findings}

\section{Chi-square Analysis}

Table 1 shows that out of 1199 respondents, 817 combine fuel-wood with electricity due to the reason of culture where single households have the majority with 382 . Meaning that single households combine fuel-wood with electricity more than married households because of culture. This result contradicts the result in the studies of Özcan et al. (2013); 
Pandey and Chaubal (2011) showing the larger the household the higher the preference for dirty energy over clean energy, possibly due to the large number of people that may not afford the cost of modern energy. Accordingly, the Chi-square test confirmed a significant relationship between marital status and fuel stacking at Pearson chi-Square value of 21.253 and the Asymp. Sig. (2-sided) 0.047).

Table 1

Marital status and household stacking behavior

\begin{tabular}{|c|c|c|c|c|c|c|}
\hline & \multicolumn{5}{|c|}{ Marital Status } & \multirow[t]{2}{*}{ Total } \\
\hline & Single & Married & Divorced & Separated & & \\
\hline Price & 51 & 45 & 22 & 25 & 0 & 143 \\
\hline Culture & 382 & 273 & 74 & 83 & 5 & 817 \\
\hline Family & 65 & 36 & 17 & 17 & 0 & 135 \\
\hline Other & 52 & 27 & 10 & 15 & 0 & 104 \\
\hline Total & 550 & 381 & 123 & 140 & 5 & 1199 \\
\hline \multicolumn{7}{|l|}{ Chi-square tests } \\
\hline & \multicolumn{2}{|c|}{ Value } & \multicolumn{2}{|c|}{ df } & & Sig. (2sided) \\
\hline Pearson Chi-Square & \multicolumn{2}{|c|}{$21.253 a$} & \multicolumn{2}{|c|}{12} & & 0.047 \\
\hline Likelihood Ratio & \multicolumn{2}{|c|}{22.117} & \multicolumn{2}{|c|}{12} & & 0.036 \\
\hline Linear-by-Linear Association & \multicolumn{2}{|c|}{1.963} & \multirow{2}{*}{\multicolumn{2}{|c|}{1}} & & 0.161 \\
\hline $\mathrm{N}$ of Valid Cases & & 99 & & & & \\
\hline
\end{tabular}

In Table 2, out of 1199 respondents, 817 in all the categories of educational level have indicated that they combine fuel-wood with electricity due to the influence of culture. Also, respondents with secondary education have the highest number (486) that combine fuel-wood with electricity due to cultural influence. The Pearson Chi-Square value is 32.736 and the Asymp. Sig. (2-sided) 0.001 indicating a significant relationship between education and combining fuel-wood with electricity. This result has confirmed the importance of education in household multi-fuel use in line with the studies of Baiyegunhi and Hassan (2014) in Nigeria and Lay et al. (2013) in Kenya that shows household education level induces them to combine fuel-wood with clean energy such as electricity, LPG and solar energy.

Table 2

EducLevel and household stacking behavior

\begin{tabular}{|c|c|c|c|c|c|c|}
\hline & & \multicolumn{4}{|c|}{ EducLevel } & \multirow[t]{2}{*}{ Total } \\
\hline & & Primary & Secondary & Certificate & Diploma & \\
\hline \multirow[t]{5}{*}{ Reason for stacking } & Price & 26 & 101 & 9 & 7 & 143 \\
\hline & Culture & 206 & 486 & 81 & 35 & 817 \\
\hline & Family & 36 & 71 & 15 & 5 & 135 \\
\hline & Other & 24 & 69 & 7 & 1 & 104 \\
\hline & Total & 292 & 727 & 112 & 48 & 1199 \\
\hline \multicolumn{7}{|l|}{ Chi-square tests } \\
\hline & \multicolumn{3}{|c|}{ Value } & \multicolumn{2}{|c|}{ df } & Asymp. Sig. (2sided) \\
\hline Pearson Chi-Square & \multicolumn{3}{|c|}{$32.736 a$} & \multicolumn{2}{|c|}{12} & 0.001 \\
\hline Likelihood Ratio & \multicolumn{3}{|c|}{30.71} & \multicolumn{2}{|c|}{12} & 0.002 \\
\hline Linear-by-Linear Association & \multicolumn{3}{|c|}{0.15} & \multirow{2}{*}{\multicolumn{2}{|c|}{1}} & \multirow[t]{2}{*}{0.699} \\
\hline $\mathrm{N}$ of Valid Cases & & 1199 & & & & \\
\hline
\end{tabular}


Table 3

Household age and household stacking behavior

\begin{tabular}{llcccccc}
\hline & \multicolumn{5}{c}{ Age } & \multicolumn{2}{c}{ Total } \\
\cline { 2 - 6 } & & $\mathbf{1 7}$ to $\mathbf{2 9}$ & $\mathbf{3 0}$ to $\mathbf{4 4}$ & $\mathbf{4 5}$ to $\mathbf{6 0}$ & $\mathbf{6 0}$ above & \\
\hline Reason for stacking & Price & 143 & 0 & 0 & 0 & 143 \\
& Culture & 0 & 817 & 0 & 0 & 817 \\
& Family & 0 & 0 & 135 & 0 & 135 \\
& Other & 0 & 0 & 0 & 104 & 104 \\
Total & & 143 & 817 & 135 & 104 & 1199 \\
\hline Chi-square tests & & & & & \\
\hline & Value & df & Asymp. Sig. (2sided) \\
\hline Pearson Chi-Square & $3597.000 a$ & 9 & & 0 & \\
Likelihood Ratio & 2333.16 & 9 & & 0 & \\
Linear-by-Linear Association & 1198 & 1 & & 0 & \\
N of Valid Cases & 1199 & & & &
\end{tabular}

The result in Table 3 indicated that out of 1199 respondents, 817 between the ages of 30 to 44 combine fuel-wood with electricity because of culture. Those in the age bracket of 30 to 44 are the highest respondents that combine fuel-wood with electricity because of culture. The Pearson Chi-Square value is 3597 and the Asymp. Sig. (2-sided) 0.000 confirmed a significant relationship between household age and fuel stacking behavior. The study of Gebreegziabher et al. (2012) in Ethiopia confirmed our findings showing age induces multi-fuel use behavior among households.

Table 4

Marital status as a reason for choosing fuel wood over electricity

\begin{tabular}{lccccc}
\hline & \multicolumn{4}{c}{ Marital Status } & \multirow{2}{*}{ Total } \\
\cline { 2 - 5 } & Single & Married & Divorced & Separated & \\
\hline A bit affordable & 51 & 45 & 22 & 25 & 143 \\
Relatively affordable & 382 & 273 & 74 & 83 & 817 \\
Affordable & 65 & 36 & 17 & 17 & 135 \\
Very affordable & 52 & 27 & 10 & 15 & 104 \\
Total & 550 & 381 & 123 & 140 & 1199 \\
\hline Chi-Square Tests & & & & & \\
\hline & Value & df & Asymp. Sig. (2sided) \\
\hline Pearson Chi-Square & $21.253 a$ & 12 & & 0.047 & \\
Likelihood Ratio & 22.117 & 12 & & 0.036 & \\
Linear-by-Linear Association & 1.963 & 1 & & 0.161 & \\
N of Valid Cases & 1199 & & & & \\
\hline
\end{tabular}

Table 4 revealed that more singles said the reason they choose fuel wood instead of electricity is because fuel wood is relatively affordable. 817 out of 1199 respondents have indicated the relative affordability of fuel wood compared to electricity. The Pearson ChiSquare test showed no significant relationship between choosing fuel wood over electricity and marital status at the value of 21.253 and the Asymp. Sig. (2-sided) 0.047.

From Table 5, respondents with secondary education said they choose fuel wood instead of electricity because it is relatively affordable. Out of 1199 respondents, 817 indicated relative affordability as the reason for using fuel wood instead of electricity. The Pearson Chi-Square value is 32.736 and the Asymp. Sig. (2-sided) 0.047 indicated a significant relationship between the reasons for choosing fuel wood over electricity and the 
education level of the households. Research into the impact of education on fuel-wood use has identified households whose heads have little or no formal education (Western education) tend to rely on fuel-wood as their major energy source than those with some background of formal education (Muller \& Yan, 2018).

Table 5

EducLevel and reason for choosing fuel wood over electricity

\begin{tabular}{|c|c|c|c|c|c|c|}
\hline & \multicolumn{4}{|c|}{ EducLevel } & & \multirow[t]{2}{*}{ Total } \\
\hline & Primary & Secondary & Certificate & Diploma & & \\
\hline $\begin{array}{l}\text { A bit affordable } \\
\text { Relatively }\end{array}$ & 26 & 101 & 9 & 7 & 0 & 143 \\
\hline The reason as Major Source SA affordable & 206 & 486 & 81 & 35 & 9 & 817 \\
\hline Affordable & 36 & 71 & 15 & 5 & 8 & 135 \\
\hline Very affordable & 24 & 69 & 7 & 1 & 3 & 104 \\
\hline Total & 292 & 727 & 112 & 48 & 20 & 1199 \\
\hline \multicolumn{7}{|l|}{ Chi-Square Tests } \\
\hline & Value & df & \multicolumn{4}{|c|}{ Asymp. Sig. (2sided) } \\
\hline Pearson Chi-Square & $32.736 a$ & 12 & \multicolumn{4}{|c|}{0.001} \\
\hline Likelihood Ratio & 30.71 & 12 & \multicolumn{4}{|c|}{0.002} \\
\hline Linear-by-Linear Association & 0.15 & 1 & \multicolumn{4}{|c|}{0.699} \\
\hline $\mathrm{N}$ of Valid Cases & 1199 & & & & & \\
\hline
\end{tabular}

Table 6

Education level and rate of fuel wood consumption

\begin{tabular}{|c|c|c|c|c|c|c|c|}
\hline & & \multicolumn{4}{|c|}{ EducLevel } & \multirow{2}{*}{\multicolumn{2}{|c|}{ Total }} \\
\hline & & Primary & Secondary & Certificate & Diploma & & \\
\hline \multirow[t]{6}{*}{ FreqMajEnergySourceSA } & Once a day & 292 & 0 & 0 & 0 & 0 & 292 \\
\hline & Twice a day & 0 & 727 & 0 & 0 & 2 & 729 \\
\hline & Trice a day & 0 & 0 & 1120 & 0 & 0 & 112 \\
\hline & Other & 0 & 0 & 0 & 48 & 0 & 48 \\
\hline & 5 & 0 & 0 & & 0 & 18 & 18 \\
\hline & Total & 292 & 727 & 112 & 48 & 20 & 1199 \\
\hline \multicolumn{8}{|l|}{ Chi-Square Tests } \\
\hline & Value & df & \multicolumn{5}{|c|}{ Asymp. Sig. (2sided) } \\
\hline Pearson Chi-Square & $4673.140 \mathrm{a}$ & 16 & \multicolumn{5}{|c|}{0} \\
\hline Likelihood Ratio & 2528.485 & 16 & \multicolumn{5}{|c|}{0} \\
\hline Linear-by-Linear Association & 1170.241 & 1 & \multicolumn{5}{|c|}{0} \\
\hline $\mathrm{N}$ of Valid Cases & 1199 & & & & & & \\
\hline
\end{tabular}

Table 6 showed more respondents with secondary education frequently use fuel wood as an energy source twice a day. The possible explanation of having more respondents with secondary education having a higher frequency of using more fuel-wood than those with primary education could be that Western Cape Province where the study is conducted is a well-educated province where you hardly find people with lower education level compared to other provinces. Out of 1199 respondents, 729 said they frequently use fuel-wood as a major energy source twice a day. The Pearson Chi-Square value is 4673.140 and the Asymp. Sig. (2-sided) 0.000 indicated that there is a significant relationship between the frequencies of using fuel wood for household activities. 
Table 7

Age and rate of fuelwood consumption

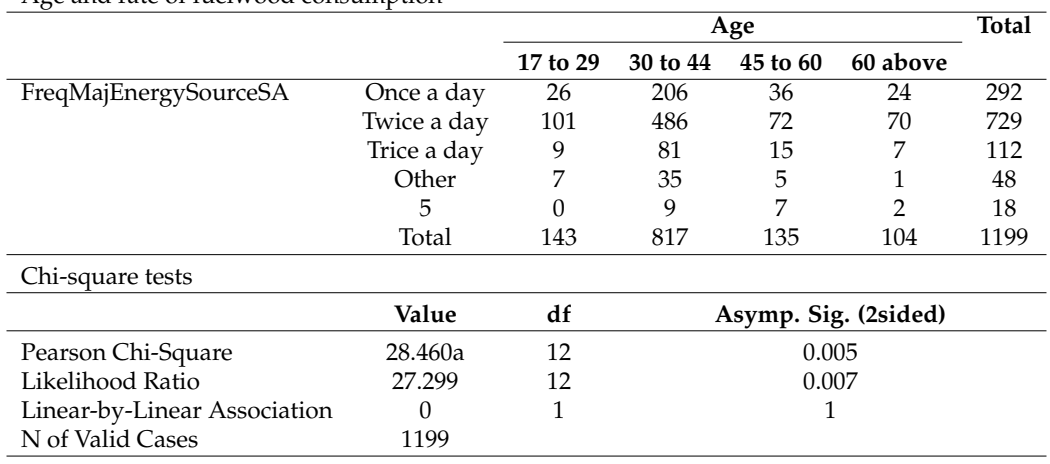

The result in Table 7 has indicated that respondents in the age bracket of 30 to 44 said they use fuel wood twice a day. Across the ages of 17 to 60, more people frequently use fuel wood as their major energy source twice a day. The Pearson Chi-Square value is 28.460 and the Asymp. Sig. (2-sided) 0.005 confirmed a significant relationship between the rates of fuel-wood use and age. Age is a demographic factor that affects household health, income, productivity, and energy consumption. Age is found to be is positively associated with preference for traditional fuels over modern fuels (Özcan et al., 2013; Muller \& Yan, 2018).

\section{Multivariate Analysis}

The probability of F-statistics for the two multivariate regression is significant at $1 \%$. This confirms the fitness of the two models. The adjusted R-square for the two models is 37.9 and $17.4 \%$. This shows that the variability of the independent variables explained the dependent variables (fuelwood consumption and stacking behavior) at $37.9 \%$ and $17.4 \%$ respectively.

The result in Table 8 shows that the age of the household influences fuel wood consumption. The higher the age of the household the higher the probability of consuming fuel wood as domestic energy at $10 \%(0,086)$. The result also indicated marital status has a positive influence on fuel wood consumption, meaning that married households tend to consume fuel wood more than the singles at $1 \%(0.001)$. Conversely, the result indicated that the education level of the household has a negative influence on fuel wood consumption, that is to say, the higher the level of education the lower the level of fuel wood consumption at $10 \%(0.063)$.

According to Table 9, age has a positive influence on household stacking behavior but the result is not significant at (0.401). Therefore, it is very difficult to draw a specific conclusion. While from the result, marital status has a positive influence on the household stacking behavior at $10 \%(0.074)$. However, the education level of the household has a negative influence on the stacking of energy at a significant level of 1 (0.003). 


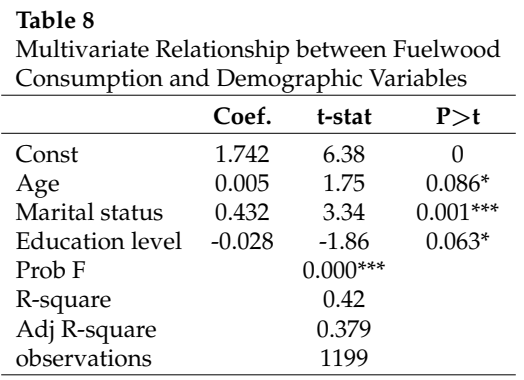

Table 9

Multivariate analysis of the Relationship between Demographic Variables and Stacking

\begin{tabular}{lccc}
\hline & Coef. & t-stat & P >t \\
\hline Const & 3.398 & 13.11 & $0.000^{* * *}$ \\
Age & 0.022 & 0.84 & 0.401 \\
Marital status & 0.219 & 1.79 & $0.074^{*}$ \\
Educational level & -0.043 & -2.95 & $0.003^{* * *}$ \\
Prob F & & $0.000^{* * *}$ & \\
R-square & & 0.216 & \\
Adj R-square & & 0.174 & \\
observations & & 1199 & \\
\hline
\end{tabular}

\section{Conclusion}

This study intends to evaluate the role of demographic factors in household decisions to consume fuel-wood instead of electricity in the Western Cape Province of South Africa. The Chi-square test was used to establish the relationship between marital status, education level, and age with stacking behavior, the reason for choosing fuel wood instead of electricity, and the rate of fuel wood consumption. The Multivariate analysis was also used to evaluate the influence of age, marital status, and education level on fuel wood consumption and stacking behavior. The outcome of the study shows a significant influence of age, marital status, and education level on the household decision to choose fuel wood as domestic energy instead of electricity. From the results, it is indicative that a clear linkage exists between households' living circumstances and the environment. Meaning that household's fuel wood consumption behaviors are on one hand influenced by their living circumstances, while on the other hand, the environment is being affected by the behavior of households' demand for environmental goods (i.e fuel-wood). Regarding this, policies that would influence the behavior of individuals such as investment in human capital and environmental education are recommended. 


\section{References}

Baiyegunhi, L., \& Hassan, M. (2014). Rural household fuel energy transition: Evidence from Giwa LGA Kaduna State, Nigeria. Energy for Sustainable Development, 20, 3035.

Démurger, S., \& Fournier, M. (2011). Poverty and firewood consumption: A case study of rural households in northern China. China Economic Review, 22(4), 512-523.

Elias, R. J., \& Victor, D. G. (2005). Energy transitions in developing countries: a review of concepts and literature. Program on Energy and Sustainable Development, Working Paper. Stanford: Stanford University.

Franks, L. (2014). The impact of rising electricity tariffs on tariffs on the urban poor: A South African case study (Unpublished master's thesis). University of Cape Town.

Franks, L., \& Prasad, G. (2014). Informal electricity re-selling-entrepreneurship or exploitation? In Twenty-second domestic use of energy (pp. 1-6).

Gebreegziabher, Z., Mekonnen, A., Kassie, M., \& Köhlin, G. (2012). Urban energy transition and technology adoption: The case of tigrai, northern ethiopia. Energy Economics, 34(2), 410-418.

Guta, D. D. (2012). Application of an almost ideal demand system (AIDS) to Ethiopian rural residential energy use: Panel data evidence. Energy Policy, 50, 528-539.

Kuunibe, N., Issahaku, H., \& Nkegbe, P. K. (2013). Wood based biomass fuel consumption in the Upper West Region of Ghana: Implications for environmental sustainability.

Lay, J., Ondraczek, J., \& Stoever, J. (2013). Renewables in the energy transition: Evidence on solar home systems and lighting fuel choice in Kenya. Energy Economics, 40, 350-359.

Link, C. F., Axinn, W. G., \& Ghimire, D. J. (2012). Household energy consumption: Community context and the fuelwood transition. Social Science Research, 41(3), 598-611.

Masera, O. R., Saatkamp, B. D., \& Kammen, D. M. (2000). From linear fuel switching to multiple cooking strategies: A critique and alternative to the energy ladder model. World Development, 28(12), 2083-2103.

Matsika, R., Erasmus, B., \& Twine, W. (2013). Double jeopardy: The dichotomy of fuelwood use in rural South Africa. Energy Policy, 52, 716-725.

Mekonnen, A., Gebreegziabher, Z., Kassie, M., \& KÖLIN, G. (2009). Income alone doesn't determine adoption and choice of fuel types. Sweden: Environment for Development.

Muazu, N. B., \& Ogujiuba, K. O. (2020). Analysis of dynamics of domestic fuelwood energy consumption in nigeria: Is fuel stacking theory apt. Journal of Science Technology and Education, 8(1), 302-317.

Muller, C., \& Yan, H. (2018). Household fuel use in developing countries: Review of theory and evidence. Energy Economics, 70, 429-439.

Ogwumike, F. O., Ozughalu, U. M., \& Abiona, G. A. (2014). Household energy use and determinants: Evidence from Nigeria. International Journal of Energy Economics and Policy, 4(2), 248-262.

Özcan, K. M., Gülay, E., \& Üçdoğruk, Ş. (2013). Economic and demographic determinants of household energy use in Turkey. Energy Policy, 60, 550-557. 
Pandey, V. L., \& Chaubal, A. (2011). Comprehending household cooking energy choice in rural india. Biomass and Bioenergy, 35(11), 4724-4731.

Taylor, M. J., Moran-Taylor, M. J., Castellanos, E. J., \& Elías, S. (2011). Burning for sustainability: biomass energy, international migration, and the move to cleaner fuels and cookstoves in Guatemala. Annals of the Association of American Geographers, 101(4), 918-928. 